\title{
Factors affecting the costs and timing of water main replacement in a water distribution network
}

\section{Conference Paper}

\section{Author(s):}

Kerwin, Sean; Adey, Bryan T.

Publication date:

2020-10

Permanent link:

https://doi.org/10.3929/ethz-b-000473278

Rights / license:

Creative Commons Attribution-NonCommercial-NoDerivatives 4.0 International 


\title{
Factors affecting the costs and timing of water main replacement in a water distribution network
}

\author{
S. Kerwin \& B. Adey \\ ETH Zürich, Zürich, Switzerland
}

\begin{abstract}
Deteriorated cast iron pipes often account for a significant portion of water main failures in a water distribution network. Such incidents cause havoc to traffic circulation, damage surrounding properties and public infrastructure, and increase the risk of water contamination. Thus, infrastructure managers often receive questions from stakeholders concerning the replacement time horizon of such pipes and the associated financial investment needs. These questions are difficult to answer as the service lifetime of buried pipes depends on a number of factors such as the rate of deterioration, the associated failure risk, the level of risk tolerance of the utility as well as the intervention planning activities of other utility networks. In addition, replacement costs depend on economies of scale as the unit cost of pipe replacement tends to decrease as length increases. Managers must consider these factors along with associated uncertainty when making estimates on replacement projections of problematic pipes. In this paper, a methodology is presented that aims to help infrastructure managers make accurate pipe replacement projections. An example is provided of the implementation on a large water distribution network.
\end{abstract}

\section{INTRODUCTION}

Cast iron mains were widely installed in water distribution networks up until the 1960s when they were superseded by ductile iron and plastic pipes due to their superior material properties. These pipes still makeup a significant portion of many networks (Rajani and Makar, 2000) and are a concern for infrastructure managers due to the brittle nature of the material. With time these pipes deteriorate and inevitably fail due to a number of reasons such as manufacturing error, poor installation, corrosion and soil movement (Makar et al., 2001). Failure typically manifests itself as a pipe rupture and results in extensive consequences to surrounding properties, traffic networks, and other buried utilities. Infrastructure managers are thus interested in estimating the intervention costs and timing of rehabilitating or replacing such pipes.

Such estimates require at a minimum the expected number of intervention sites and the corresponding pipe length so that fixed and variable costs can be calculated. Fixed costs refer to mobilization and intervention site preparation and depend on the type of intervention being executed, and the site characteristics (e.g. traffic level, zoning). Variable costs are length dependent and include the costs of excavation, transportation and installation of pipe segments, which depend on pipe diameter, material, length and intervention type. In order to improve the accuracy of these estimates infrastructure managers must consider the cost-savings potential of economies of scale. Specifically, estimates should include contiguous discounts, coordination discounts and quantity discounts for all possible intervention types that could be executed. Contiguity discounts arise when interventions are executed on multiple adjacent pipes simultaneously. The fixed costs of mobilization and intervention site preparation are applied only once to the group of pipes instead of each pipe separately. The cost savings potential of coordinating interventions with other utilities depends on the lateral distance between pipes, the intervention types being considered (i.e. open trench vs trenchless intervention types) as well as the depth at which the infrastructure (e.g. pipes, road surface, etc.) of the partner utility is located. Quantity discounts are commonly offered by contractors on large intervention sites in an effort to win bids and depend on the intervention size and type of intervention being executed.

These considerations have been previously applied to water distribution networks (Nafi and Kleiner, 2009a, Kleiner et al., 2010, Nafi and Kleiner, 2009b) but did not investigate the tradeoff between increased computational complexity and cost reduction that results from pipe contiguity, only considered one intervention type (open trench) and only intervention planning activities of the road network. This paper builds on previous work by investigating the tradeoff that re- 
sults from including contiguity discounts in cost estimates, considers the uncertainty of the planning activities of three utility networks (sewer, gas and road) on estimates, multiple intervention types, quantity discounts from contractors and the variability of fixed costs and variable costs. The analysis is applied to a large water distribution network.

\section{METHODOLOGY}

The applied methodology is discussed in detail in Kerwin and Adey (2020) and consists of 5 steps summarized below:

1. Model network, failures and interventions

2. Define intervention strategies

3. Identify candidate interventions

4. Perform cost-benefit analysis

5. Optimize within constraints

Firstly, all models used to describe the infrastructure, relevant failures and possible intervention types are determined. To describe the network, a grouping algorithm is first used to aggregate adjacent pipe segments that have the same material, diameter and a similar year of installation. This process forms pipe objects, which are indivisible, meaning that preventive interventions can only be executed on the entire length of the pipe object and not on portions of it. Pipe objects are then categorized based on function (i.e. service line, distribution main) and pipe material.

Monetized failure risk, defined as the product of failure probability and failure consequence, is quantified for all pipe objects using appropriate models. Risk is used in the cost-benefit analysis to determine the benefit of executing a preventive intervention. Possible intervention types are then identified per category and the models to estimate costs of intervention execution to the utility and public (i.e. temporary service interruption, traffic disruption) are defined.

Next, intervention strategies are defined for all categories of interest. A strategy describes how infrastructure should ideally be maintained without consideration of constraints and consists of a pipe category, an intervention triggering criteria such as age, risk level, failure rate threshold, and the corresponding intervention type that should be executed. These defined strategies are then used to identify pipe objects that require a preventive intervention.

A cost-benefit analysis is then performed on all decision variables. Decision variables consist of the set of possible combinations of interventions of different types and considered groupings of contiguous pipe objects. Costs include the cost to the water utility of executing the preventive intervention and costs to the public in terms of temporary service interruption and traffic disruption during intervention execution. Benefit is calculated as the amount of risk reduced by executing the preventive intervention and depends on the effectiveness of the intervention. Replacement interventions reduce the risk completely, whereas other intervention types (e.g. non-structural relining) only achieve a partial reduction.

The results of the cost-benefit analysis are then used to determine the set of interventions that maximizes net benefit, while respecting relevant constraints such as pipe objects can only appear in one grouping and any specified annual budget constraints.

Discounts are applied during the cost-benefit analysis step. In order to better understand the effect of discounts on overall estimates, a step-wise approach is used beginning with contiguity and quantity discounts on open trench interventions. This is followed by coordination and quantity discounts on open trench interventions. These results are then benchmarked to the effects of a 10 percent increase in fixed and variable costs. Trenchless techniques are then considered with corresponding quantity discounts.

\subsection{Consideration of contiguity discounts}

Contiguity discounts affect the fixed costs of executing interventions and apply to all intervention types. In order to investigate the influence of contiguity in pipe replacement estimates, the connectivity of pipe objects is needed. A graph structure composed of vertices (pipe objects) and edges (information on connectivity) is built using the adjacency matrix of the network. Degrees of separation are used to control the extent of grouping. A grouping of degree of zero consists of only the pipe object, a grouping of degree one consists of the pipe object and an immediate neighbors, a grouping of degree two consists of the pipe object, an immediate neighbor and a third pipe object, connected to the pipe object via the immediate neighbor. Unique groupings of pipe objects up to 4 degrees of separation are considered in this study. This was implemented in R (Core Team, 2013) using the igraph package (Csardi, 2015). An upper limit of $2 \mathrm{~km}$ is applied to total length of considered groupings.

\subsection{Consideration of coordination discounts}

Discounts on fixed and variable costs arise from coordinating interventions with adjacent networks if common trenches can be prepared, and the costs of intervention site preparation and excavation shared. Thus, coordination discounts only apply to open trench interventions. The magnitude of the discount depends on the depth of the infrastructure of the coordinating partner. Thus, the highest savings occur from coordination with the sewer network and the lowest from the road network.

Typically, the intervention planning activities of other infrastructure networks are not known well in advance making their consideration in preventive intervention planning difficult. This uncertainty is mod- 
elled in this paper by stochastically generating the expected number of coordination opportunities that will arise in a given year due to intervention activities on the sewer, gas and road networks and then randomly assigning these opportunities to pipe objects in the network. Numerous simulation runs are used to assess the effect of this uncertainty on cost estimates.

Furthermore, timeframe is important when considering coordination discounts. The longer the timeframe, the more opportunities there will be to coordinate with adjacent infrastructure networks, which will result in greater savings. Concurrently, the number of expected coordination opportunities become more uncertain with greater timeframes. Thus, a timeframe of 5 years is used to limit the effect of uncertainty on the evaluation of coordination discounts.

\subsection{Consideration of quantity discounts}

Quantity discounts are applied to the variable costs of intervention execution above specified quantity thresholds and depend on intervention type. For example, quantity discounts for open trench interventions are typically higher than trenchless interventions because it is the traditional technique used in industry to renew buried infrastructure and can be executed by all contractors whereas trenchless techniques require additional specialized knowledge and equipment and may not be not offered by local contractors. As considerations of contiguity and coordination affect quantity, discounts on quantity are considered at the same time as contiguity and coordination discounts.

\subsection{Consideration of intervention type}

Open trench and structural trenchless interventions are considered such as pipe bursting and swagelining. Studies have investigated the cost effectiveness of cathodic protection to extending the service lifetime of cast iron pipes and have demonstrated its usefulness (Rajani and Kleiner, 2007, Kleiner and Rajani, 2004), however, it is not a renewal technique (Infraguide, 2003 ) and thus is not considered in.this paper.

Several simplifying assumptions are made. Firstly, no difference is made between considered trenchless techniques. In reality, the differences are important and the choice depends on many factors such as soil properties, proximity of adjacent infrastructure, pressure requirements, etc. For example, swagelining may be chosen over pipe bursting if the slight diameter reduction is deemed inconsequential to pressure levels and the lateral distance to adjacent buried infrastructure is sufficiently low that they could be damaged by pipe bursting. These considerations require detailed site-level information, which was not available.

The fixed costs of site preparation are assumed to be the same for open trench and trenchless interventions. Open trench requires more coordination with municipal traffic authorities, traffic diversion signs, etc., whereas trenchless interventions require pipe cleaning, video inspection detailing location of repair clamps, valves and excavation pits at the entry and exit points of the intervention and at service lines, valves and hydrants.

The variable costs are estimated to be significantly lower for trenchless interventions as the time requirements for intervention execution are significantly lower and excavation costs are greatly reduced (Jäggi, 2018, Zhao and Rajani, 2002).

Furthermore, trenchless interventions are not considered on groupings less than $100 \mathrm{~m}$ in length or containing pipe objects with a service line density greater than 20 per $100 \mathrm{~m}$, which is a known rule of thumb (Infraguide, 2003). Of course trenchless interventions can be executed on smaller lengths in specific situations (e.g. pipe is located under train tracks or busy intersection) but as fewer contractors offer trenchless intervention services the assumption was made that a certain length threshold would have to be surpassed.

\section{CASE STUDY}

Data from a large water utility is used. Table 1 summarizes the pipe objects of the network.

Table 1. Summary characteristics of pipe objects.

\begin{tabular}{lrr}
\hline Parameter & All pipe objects & Cast iron pipes objects \\
\hline $\begin{array}{l}\text { Number } \\
\text { Diameter } \\
\text { (mm) }\end{array}$ & 8815 & 1287 \\
$\begin{array}{l}\text { Pipe object } \\
\text { length (m) }\end{array}$ & $100-1000$ & $100-500$ \\
Total length & 1267.6 & $15-1552.5$ \\
(km) & & 159.2 \\
$\begin{array}{l}\text { Installation } \\
\text { year }\end{array}$ & $1903-2015$ & $1903-1969$ \\
\hline
\end{tabular}

Table 2, 3, and 4 contains the relevant parameters used for the estimates of unit cost of pipe replacement in monetary units (m.u.).

Table 2. Fixed costs (m.u.) of intervention execution.

\begin{tabular}{lrrr}
\hline Intervention & \multicolumn{3}{c}{ Zoning } \\
\cline { 2 - 4 } & Downtown & Residential & Rural \\
\hline Open trench & 12 & 10 & 7 \\
Trenchless & 12 & 10 & 7 \\
\hline
\end{tabular}

Table 3. Variable costs (m.u./m) of intervention execution on cast iron pipes.

\begin{tabular}{llll}
\hline \multirow{2}{*}{ Intervention } & \multicolumn{3}{c}{ Pipe type (function) } \\
\cline { 2 - 4 } & Distribution & Transmission \\
\hline Open trench & 1.56 & 2.50 \\
Trenchless & 1.09 & 1.50 \\
\hline
\end{tabular}


To account for differences in variable cost due to diameter it is assumed that the variable cost of the largest pipe will be $10 \%$ higher than that of the smallest pipe in a given category, defined by function and material. Linear interpolation is then applied to all other pipes in the category. The values in Table 3 are applied to the pipes with the smallest diameter.

Table 4. Parameters used to calculate discounts.

\begin{tabular}{lrr}
\hline Discount type & Criteria & Discount (\%) \\
\hline Coordination, road & & 10 \\
Coordination, gas & & 20 \\
Coordination, sewer & & 30 \\
Quantity, open trench & $50-100$ m.u. & 10 \\
Quantity, open trench & $100-200$ m.u. & 20 \\
Quantity, open trench & $>200$ m.u. & 30 \\
Quantity, trenchless & $>300$ m.u. & 10 \\
\hline
\end{tabular}

To ensure that all distribution and transmission cast iron pipes were replaced in the estimates, an agebased intervention strategy was set that all cast iron pipes above 40 years must be replaced.

\section{RESULTS}

\subsection{Influence of contiguity and quantity discounts}

Table 5 and Table 6 contain the values used to estimate unit cost of pipe replacement when contiguity (degree of separation) and quantity discounts are applied to open trench interventions. Trenchless interventions and coordination discounts are ignored.

Table 5. Summary of estimates when contiguity and quantity discounts are varied.

\begin{tabular}{|c|c|c|c|c|c|c|}
\hline . & 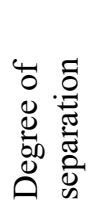 & 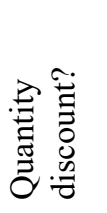 & 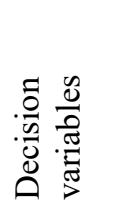 & 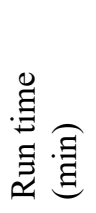 & 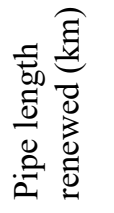 & 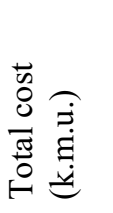 \\
\hline 1 & 0 & no & 8798 & 0.3 & 159.2 & 270.4 \\
\hline 2 & 1 & no & 19393 & 0.8 & 159.3 & 268.3 \\
\hline 3 & 2 & no & 40068 & 1.8 & 159.4 & 268.0 \\
\hline 4 & 3 & no & 72832 & 3.3 & 159.4 & 267.8 \\
\hline 5 & 4 & no & 117909 & 6.1 & 159.4 & 267.9 \\
\hline 6 & 0 & yes & 8798 & 0.3 & 159.2 & 205.7 \\
\hline 7 & 1 & yes & 19393 & 0.7 & 160.0 & 200.2 \\
\hline 8 & 2 & yes & 40068 & 1.6 & 160.3 & 199.1 \\
\hline 9 & 3 & yes & 72832 & 3.5 & 160.4 & 199.0 \\
\hline 10 & 4 & yes & 117909 & 6.3 & 160.5 & 199.0 \\
\hline
\end{tabular}

The results of the estimates are shown in unit cost of pipe replacement (see Table 6 and Figure 1) because the total pipe length renewed varies slightly between the estimates depending on the selected groupings. The total renewed length is greater than the total length of cast iron pipes in the network because pipe objects of other materials that were adjacent to cast iron pipe objects would be included in the selected grouping if the cost-benefit analysis indicated that it was advantageous. It is evident from Figure 1 that the effect of including quantity discounts is significantly higher than discounts from contiguity. Beyond a degree of separation of two, the reduction in unit replacement cost was minimal. This is due to the costbenefit analysis, which accounts for increased impacts to traffic and service as groupings increase in size. Thus at a certain point these impacts outweigh the contiguity discounts.

Table 6. Unit cost estimates of replacement when contiguity and quantity discounts are varied.

\begin{tabular}{|c|c|c|c|c|c|c|}
\hline 莺 & 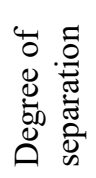 & 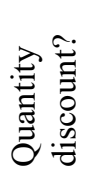 & 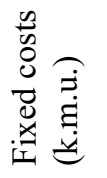 & 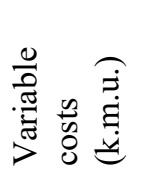 & 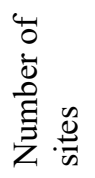 & 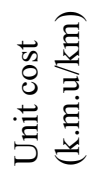 \\
\hline 1 & 0 & no & 13.6 & 256.8 & 1287 & 1.698 \\
\hline 2 & 1 & no & 11.3 & 257.0 & 1063 & 1.684 \\
\hline 3 & 2 & no & 10.8 & 257.2 & 1012 & 1.681 \\
\hline 4 & 3 & no & 10.6 & 257.2 & 998 & 1.680 \\
\hline 5 & 4 & no & 10.6 & 257.3 & 992 & 1.681 \\
\hline 6 & 0 & yes & 13.7 & 192.0 & 1287 & 1.292 \\
\hline 7 & 1 & yes & 11.2 & 189.0 & 1049 & 1.251 \\
\hline 8 & 2 & yes & 10.5 & 188.6 & 986 & 1.242 \\
\hline 9 & 3 & yes & 10.3 & 188.7 & 967 & 1.241 \\
\hline 10 & 4 & yes & 10.2 & 188.8 & 960 & 1.240 \\
\hline
\end{tabular}

Figure 1 shows the unit cost versus the maximum degree of separation considered.

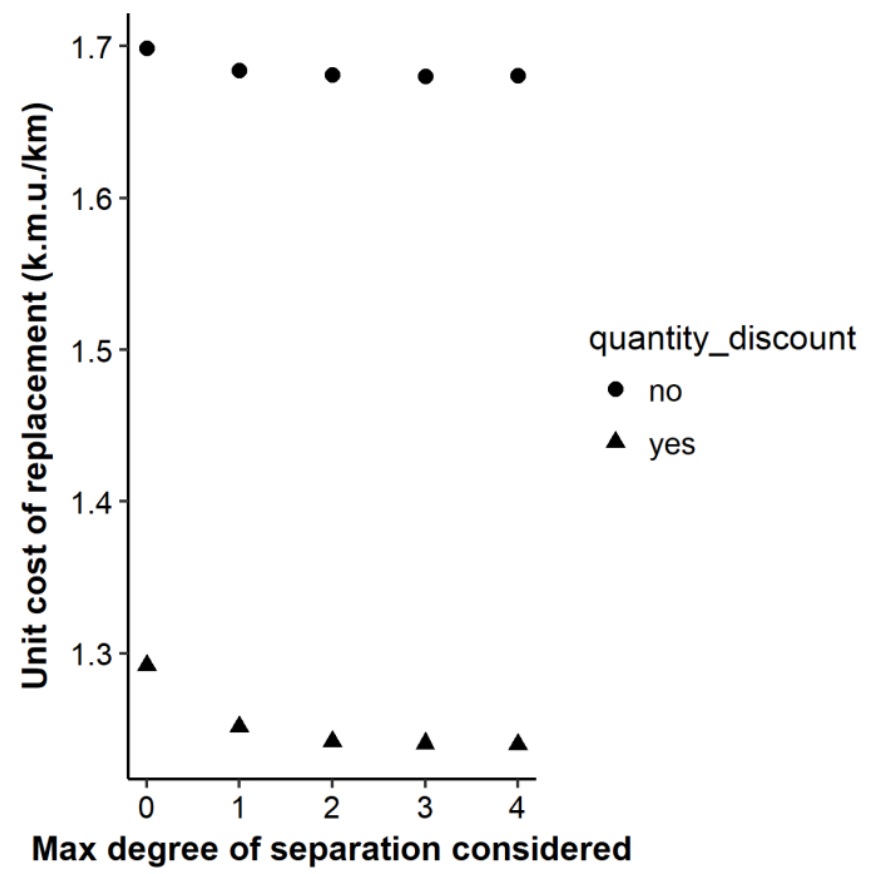

Figure 1. Results of results of contiguity vs quantity discounts. 


\subsection{Influence of coordination and quantity discounts, parameter variation and intervention type}

The influence of coordination discounts was investigated by generating a varying number of coordination opportunities per year based on a uniform distribution annd assignedto pipe objects over a 5-year period. Only those coordination opportunities affecting cast iron pipes are considered for execution. Per estimate, 100 simulations are carried out. A $10 \%$ increase of fixed and variable costs is applied to estimates 13 and 14 respectively to serve as a benchmark. In estimates 11 to 14 only open trench interventions are considered. Both open trench and trenchless interventions are considered in estimates 15 and 16. Table 7 provides a summary and Table 8 detailed results in terms of the minimum, mean and maximum values.

Table 7. Parameters of coordination estimates.

\begin{tabular}{|c|c|c|c|c|}
\hline . & & 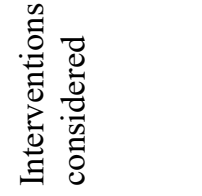 & 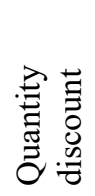 & 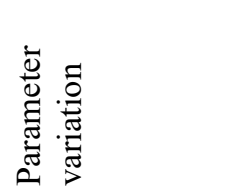 \\
\hline 11 & 100 & Open trench & No & \\
\hline 12 & 100 & Open trench & Yes & \\
\hline 13 & 100 & Open trench & Yes & $\begin{array}{l}10 \% \text { increase of } \\
\text { fixed costs }\end{array}$ \\
\hline 14 & 100 & Open trench & Yes & $\begin{array}{l}10 \% \text { increase of } \\
\text { variable costs }\end{array}$ \\
\hline 15 & 100 & $\begin{array}{l}\text { Open trench } \\
\& \text { trenchless }\end{array}$ & Yes & \\
\hline 16 & 100 & $\begin{array}{l}\text { Open trench } \\
\& \text { trenchless }\end{array}$ & No & \\
\hline
\end{tabular}

Figure 2 shows the effect of quantity discounts on unit cost of replacement.

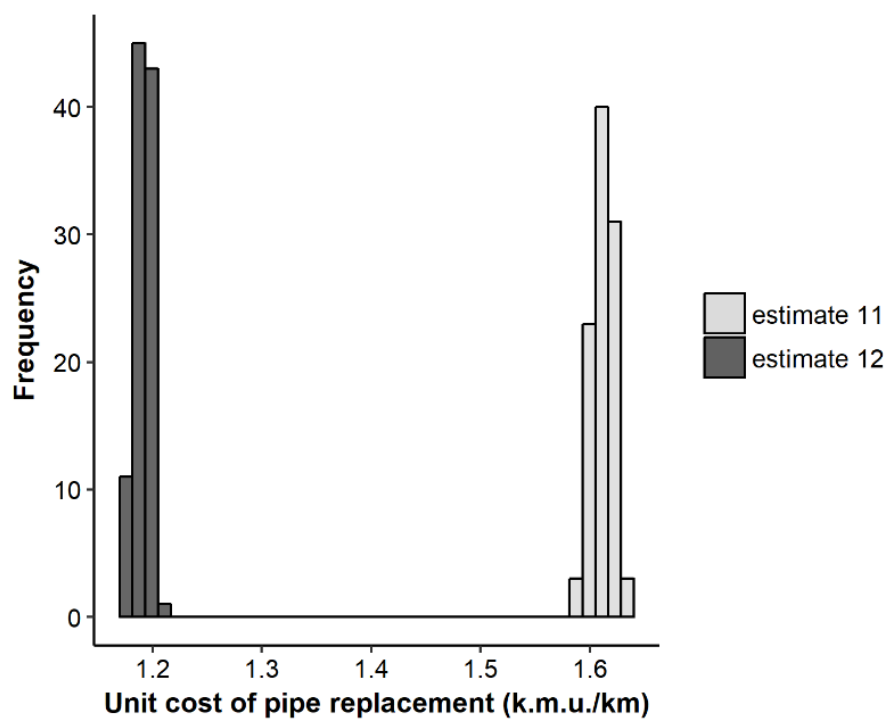

Figure 2. Histograms of unit cost of pipe replacement when coordination is considered and quantity discounts varied.
Figure 3 illustrates the effects of including quantity discount versus increases to parameters used to calculate fixed and variable costs on unit replacement cost. The inclusion of quantity discounts (estimate 12 vs 11) had the largest impact on unit cost followed by a $10 \%$ increase to variable costs (estimate 12 vs 14 ) and a $10 \%$ increase to fixed costs (estimate 12 vs 13 ).

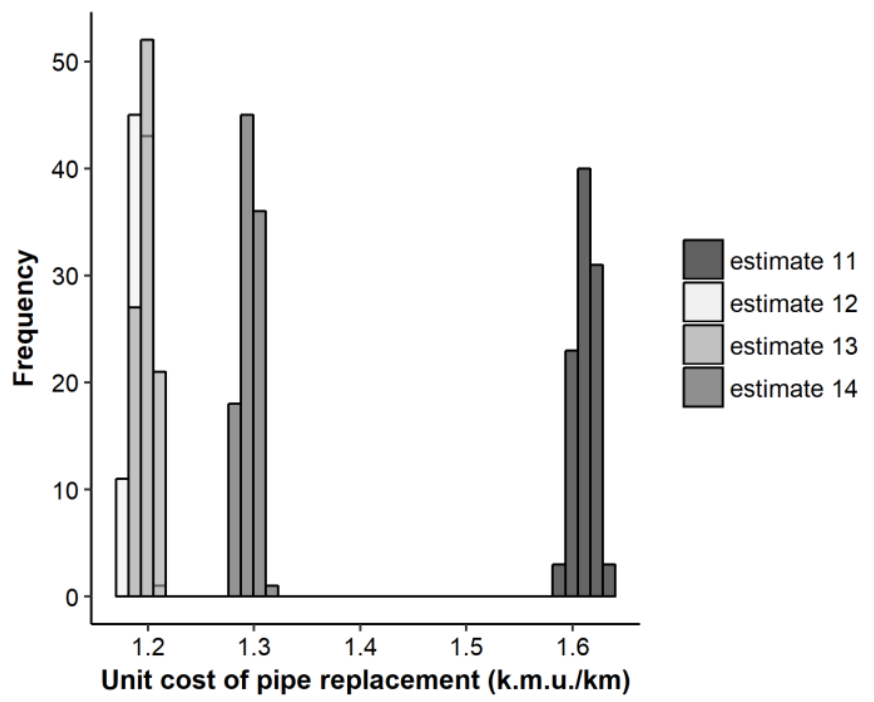

Figure 3. Histograms of unit cost of replacement when fixed cost and variable cost parameters as well as quantity discounts are varied.

Table 8. Coordination unit cost estimates.

\begin{tabular}{|c|c|c|c|c|c|c|}
\hline 莺 & & 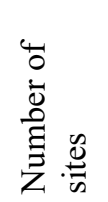 & 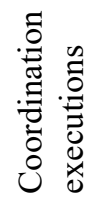 & 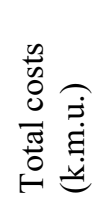 & 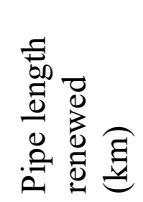 & 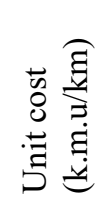 \\
\hline 11 & $\begin{array}{l}\text { min- } \\
\text { mean- } \\
\max \end{array}$ & $\begin{array}{l}1026- \\
\mathbf{1 0 4 1 -} \\
1055\end{array}$ & $\begin{array}{l}135- \\
195- \\
251\end{array}$ & $\begin{array}{l}253.6- \\
\mathbf{2 5 7 . 6}- \\
260.8\end{array}$ & $\begin{array}{l}159.5- \\
\mathbf{1 5 9 . 8}- \\
160.4\end{array}$ & $\begin{array}{l}1.590 \\
\mathbf{1 . 6 1 2}- \\
1.634\end{array}$ \\
\hline 12 & $\begin{array}{l}\min - \\
\text { mean- } \\
\max \end{array}$ & $\begin{array}{l}994- \\
\mathbf{1 0 0 9 -} \\
1022\end{array}$ & $\begin{array}{l}141- \\
\mathbf{2 0 5}- \\
259\end{array}$ & $\begin{array}{l}189.0- \\
\mathbf{1 9 1 . 9 -} \\
194.1\end{array}$ & $\begin{array}{l}160.6- \\
\mathbf{1 6 1 . 0 -} \\
161.6\end{array}$ & $\begin{array}{l}1.176- \\
\mathbf{1 . 1 9 2} \\
1.208\end{array}$ \\
\hline 13 & $\begin{array}{l}\text { min- } \\
\text { mean- } \\
\max \end{array}$ & $\begin{array}{l}993- \\
\mathbf{1 0 0 7 -} \\
1019\end{array}$ & $\begin{array}{l}141- \\
\mathbf{2 0 5}- \\
259\end{array}$ & $\begin{array}{l}190.0- \\
\mathbf{1 9 2 . 9}- \\
195.1\end{array}$ & $\begin{array}{l}160.6- \\
\mathbf{1 6 1 . 0 -} \\
161.6\end{array}$ & $\begin{array}{l}1.182- \\
\mathbf{1 . 1 9 8} \\
1.214\end{array}$ \\
\hline 14 & $\begin{array}{l}\text { min- } \\
\text { mean- } \\
\max \end{array}$ & $\begin{array}{l}995- \\
\mathbf{1 0 1 1 -} \\
1023\end{array}$ & $\begin{array}{l}144- \\
207- \\
261\end{array}$ & $\begin{array}{l}205.4- \\
\mathbf{2 0 8 . 6 -} \\
211.1\end{array}$ & $\begin{array}{l}160.5- \\
\mathbf{1 6 1 . 0 -} \\
161.6\end{array}$ & $\begin{array}{l}1.279- \\
\mathbf{1 . 2 9 6} \\
1.314\end{array}$ \\
\hline 15 & $\begin{array}{l}\min - \\
\text { mean- } \\
\max \end{array}$ & $\begin{array}{l}976- \\
992- \\
1005\end{array}$ & $\begin{array}{l}138- \\
\mathbf{2 0 2}- \\
256\end{array}$ & $\begin{array}{l}180.8- \\
\mathbf{1 8 3 . 1 -} \\
185.3\end{array}$ & $\begin{array}{l}160.9- \\
\mathbf{1 6 1 . 4 -} \\
162.1\end{array}$ & $\begin{array}{l}1.123- \\
\mathbf{1 . 1 3 4} \\
1.147\end{array}$ \\
\hline 16 & $\begin{array}{l}\text { min- } \\
\text { mean- } \\
\text { max }\end{array}$ & $\begin{array}{l}989- \\
\mathbf{1 0 0 6 -} \\
1024\end{array}$ & $\begin{array}{l}137- \\
197- \\
252\end{array}$ & $\begin{array}{l}204.7- \\
\mathbf{2 0 6 . 5}- \\
209.6\end{array}$ & $\begin{array}{l}161.0- \\
\mathbf{1 6 1 . 3 -} \\
161.9\end{array}$ & $\begin{array}{l}1.269 \\
\mathbf{1 . 2 8 0} \\
1.298\end{array}$ \\
\hline
\end{tabular}

Figure 4 shows the effects of including trenchless interventions and quantity discounts on unit replacement cost. The effect of quantity discount on unit replacement cost is highest when only open trench interventions are considered (estimate 11 vs 12) and 
decreases when both intervention types are considered (estimate 15 vs 16). The consideration of trenchless interventions had a much more significant reduction on unit cost of pipe replacement when quantity discounts are ignored (estimate 11 vs 16) and had a moderate effect when quantity discounts are applied to both intervention types (estimate 12 vs 15 ).

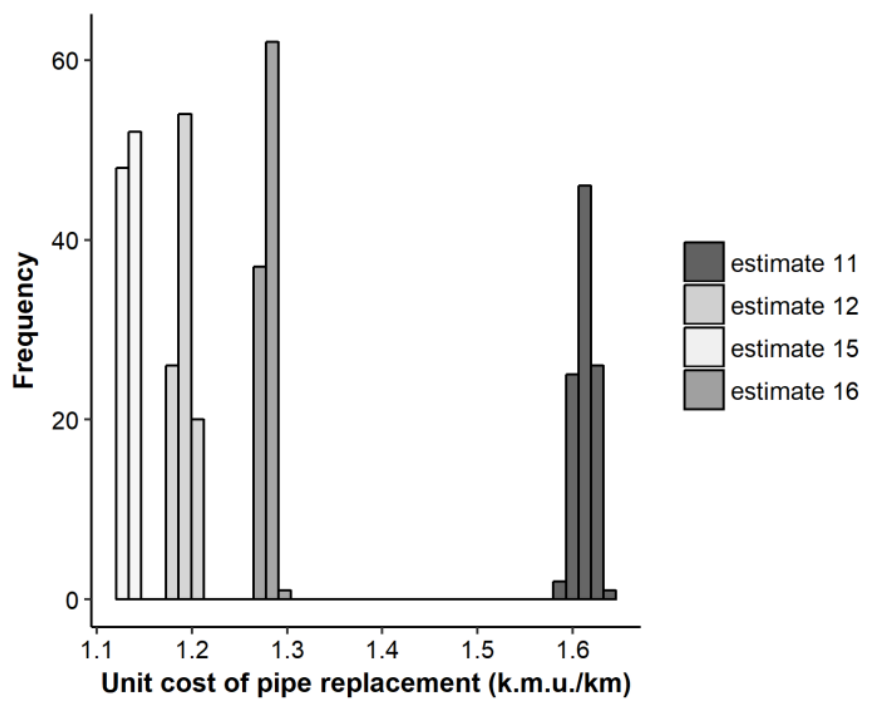

Figure 4. Histograms of unit replacement cost when intervention type and quantity discounts are varied.

Table 9 summarizes all 16 estimates of unit replacement cost in terms of relevant parameters.

Table 9. Summary of unit replacement cost estimates.

\begin{tabular}{|c|c|c|c|c|c|c|c|}
\hline 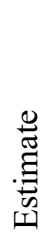 & 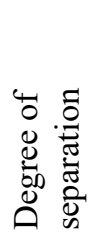 & 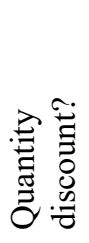 & 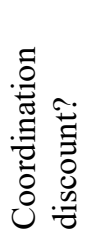 & 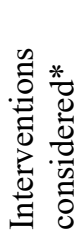 & 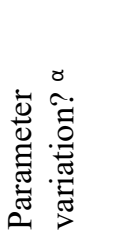 & 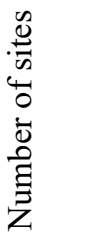 & 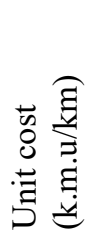 \\
\hline 1 & 0 & no & no & $\mathrm{O}$ & no & 1287 & 1.698 \\
\hline 2 & 1 & no & no & $\mathrm{O}$ & no & 1063 & 1.684 \\
\hline 3 & 2 & no & no & $\mathrm{O}$ & no & 1012 & 1.681 \\
\hline 4 & 3 & no & no & $\mathrm{O}$ & no & 998 & 1.680 \\
\hline 5 & 4 & no & no & $\mathrm{O}$ & no & 992 & 1.681 \\
\hline 6 & 0 & yes & no & $\mathrm{O}$ & no & 1287 & 1.292 \\
\hline 7 & 1 & yes & no & $\mathrm{O}$ & no & 1049 & 1.251 \\
\hline 8 & 2 & yes & no & $\mathrm{O}$ & no & 986 & 1.242 \\
\hline 9 & 3 & yes & no & $\mathrm{O}$ & no & 967 & 1.241 \\
\hline 10 & 4 & yes & no & $\mathrm{O}$ & no & 960 & 1.240 \\
\hline 11 & 2 & no & yes & $\mathrm{O}$ & no & 1041 & 1.612 \\
\hline 12 & 2 & yes & yes & $\mathrm{O}$ & no & 1009 & 1.192 \\
\hline 13 & 2 & yes & yes & $\mathrm{O}$ & $1.1 * \mathrm{fc}$ & 1007 & 1.198 \\
\hline 14 & 2 & yes & yes & $\mathrm{O}$ & $1.1 * \mathrm{vc}$ & 1011 & 1.296 \\
\hline 15 & 2 & yes & yes & $\mathrm{O}, \mathrm{T}$ & no & 992 & 1.134 \\
\hline 16 & 2 & no & yes & $\mathrm{O}, \mathrm{T}$ & no & 1006 & 1.280 \\
\hline
\end{tabular}

*O-Open trench, T-Trenchless, ${ }^{\alpha}$ (f)vc - (fixed) variable cost

\section{DISCUSSION}

The impact of discounts due to contiguity, coordination, and quantity as well the effects of the variation of parameter values and intervention type depend largely on whether the fixed cost or variable cost component of the unit cost estimates is affected. Discounts that affected the variable cost component such as quantity discounts, as well as the consideration of trenchless interventions had a larger impact on the unit replacement cost than discounts affecting only the fixed cost component (e.g. contiguity discounts).

Contiguity effects were investigated by increasing the maximum degree of separation considered. This increase resulted in an exponential increase in the number of decision variables in the cost-benefit analysis and subsequent run time (see Table 5) but significantly reduced the number of separate intervention sites (see Table 6) resulting in a reduction in fixed costs of $20 \%-23 \%$ when a degree of separation of two was considered instead of zero. The benefits of considering contiguity discounts were higher when combined with quantity discounts. For example, the reduction in unit replacement cost from estimates 1 and 3 (1.698 - 1.681 k.m.u. $/ \mathrm{km}=0.017$ k.m.u. $/ \mathrm{km})$ versus those of estimates 6 and $8(1.292-1.242$ k.m.u. $/ \mathrm{km}=0.05$ k.m.u. $/ \mathrm{km})$, is almost three times higher when quantity discounts are considered and represented a $3.9 \%$ reduction in the unit replacement cost in the example. Due to the tradeoff between reduced fixed costs and increased run time due to contiguity considerations (see Table 6), a max degree of separation of two was used for estimates 11 to 16 . Figure 1 illustrates that beyond a max degree of separation of two, the reduction in unit replacement cost is minimal.

The uncertainty resulting from the consideration of coordination discounts was quantified by performing 100 simulations per estimate and then examining the minimum, mean and maximum resulting unit replacement costs (see Table 8). When open trench interventions alone were considered, the difference between minimum and maximum unit replacement costs ranged from 0.031 to 0.044 k.m.u. $/ \mathrm{km}$ and dropped to 0.024 k.m.u. $/ \mathrm{km}$ when trenchless interventions were considered. The unit cost histograms are shown in Figures 2, 3 and 4, which illustrate that the variance in unit cost caused by coordination interventions is relatively low. Compared to the estimates that only considered contiguity and quantity discounts, the additional consideration of coordination discount resulted in a further $4 \%$ reduction in unit replacement cost (see estimates 8 vs $12,(1.242-1.192$ k.m.u. $/ \mathrm{km})$ $/ 1.242$ k.m.u. $/ \mathrm{km})$.

The previously mentioned reductions in unit cost of replacement were benchmarked against a $10 \%$ increase in the fixed and variable cost parameters. The $10 \%$ change to fixed cost parameters resulted in a 
minor increase of $0.006 \mathrm{k} . \mathrm{m} . \mathrm{u} . / \mathrm{km}$ to the unit replacement cost (see estimate 13 and 12, $1.198-1.192$ k.m.u. $/ \mathrm{km}$ ). In contrast, the impact to the unit cost was more than 17 times greater at 0.104 k.m.u. $/ \mathrm{km}$ when variable cost parameters were increased by the same amount (see estimate 14 and 12, 1.296-1.192 k.m.u. $/ \mathrm{km}$ ). The benchmark showed that the inclusion of quantity discounts and trenchless interventions had a greater impact on unit replacement cost than a $10 \%$ increase of variable cost parameters. The inclusion of contiguity and coordination discounts had a more profound effect on unit cost estimates than a $10 \%$ increase of fixed cost parameters but was lower than a $10 \%$ increase of variable cost parameters.

The additional consideration of trenchless pipe replacement techniques significantly reduced the unit cost of replacement from $1.612 \mathrm{k} . \mathrm{m} . \mathrm{u} . / \mathrm{km}$ down to $1.280 \mathrm{k} . \mathrm{m} . \mathrm{u} . / \mathrm{km}$ when quantity discounts were not considered (see estimate 11 and 16) and had a more modest reduction when quantity discounts were included (see estimate 12 and 15, 1.134 k.m.u./km vs 1.192 k.m.u. $/ \mathrm{km})$. In addition, when quantity discounts were applied, the portion of pipes replaced with open trench interventions increased due to the higher discounts offered on such interventions compared to trenchless interventions. For example, the portion of pipe replaced using open trench interventions dropped from $75.1 \mathrm{~km}$ or $46.5 \%$ of the total (see estimate 15) to $51.2 \mathrm{~km}$ or $31.7 \%$ of the total (see estimate 16).

The lowest overall unit cost estimate was 1.134 k.m.u./km (see estimate 15) and occurring using a max degree of separation of 2 , coordination and quantity discounts and the possibility of executing open trench and trenchless interventions. This estimate was $33.2 \%$ lower than the highest estimate of 1.698 k.m.u./km (see estimate 1). This is a strong indication that contiguity, coordination and quantity discounts as well as multiple intervention types should be considered when making network level replacement cost estimates of pipes.

Of course, the actual magnitude of these discounts depends largely on the values of the parameters found in Tables 2, 3 and 4. In this paper, these values serve merely to illustrate how such discounts can be included in estimates of unit cost of pipe replacement. The values of such parameters will differ between utilities and thus separate studies are required for accurate parameter estimates. For example, coordination discounts depend not only on the relative depths of the adjacent infrastructure networks to buried water pipes but also on lateral proximity. This will largely determine whether it is possible to plan and excavate common trenches and reduce costs. In addition, intervention coordination is a multi-stakeholder negotiation. In this paper, coordination is modelled as an inflexible external input. In reality, the water utility can influence and initiate coordination opportunities. Studies have modelled the dynamics of multi- stakeholder decision making in intervention coordination (van Riel et al., 2017) and several algorithms have been developed that consider the benefits of grouping spatially proximate infrastructure components of multiple municipal networks for the purposes of coordinated intervention planning (Carey and Lueke, 2013, Tscheikner-Gratl et al., 2016, Kielhauser et al., 2016, Kielhauser and Adey, 2018).

Furthermore, instead of cast iron pipes, these unit replacement cost estimates could be repeated for other pipe groups defined by any relevant attribute such as material, age, failure history or risk level depending on the preferences of the infrastructure manager.

In addition to costs, stakeholders are interested in the time horizon of replacement, which depends on the projected number of intervention sites needed, the planning requirements per site and the planning capacity of the utility (i.e. the number of sites that can be handled concurrently). This paper only investigated the number of intervention sites. The results (see Table 9) showed that the inclusion of contiguity, quantity discounts and trenchless interventions reduced the number of intervention sites whereas coordination discounts increased them (estimate 3 vs estimate 11; estimate 8 vs estimate 12). This was due to the random allocation of coordination opportunities throughout the network, which resulted in a greater number of smaller intervention sites. Comparing estimate 1 and 15, a drop of $23 \%$ in the number of required intervention sites was achieved by considering quantity, contiguity, and trenchless interventions. This drop was followed by an increase in the average size of intervention site from $123.7 \mathrm{~m}$ to $162.7 \mathrm{~m}$.

Per intervention site there is a fixed amount of planning time needed for administrative paperwork, stakeholder communication, and coordination with municipal authorities, utilities and contractors. As the size of the intervention site increases and becomes more complex, it is possible that planning efforts will require more time. Whether or not a decrease in the number of intervention sites translates to a decrease in planning time depends on the tradeoff between the amount of time saved by having fewer projects versus the additional planning time needed due to increased site complexity. More investigation is needed to answer this question.

\section{CONCLUSION}

Infrastructure managers are entrusted with the planning and execution of interventions on components of water distribution networks to maintain the level of provided service above minimum levels of acceptability. Deteriorated cast iron pipes are of particular concern due to the magnitude of failure consequences resulting from pipe rupture and the prevalence of such pipes in existing networks. Thus, the 
replacement cost and timing of such pipes is of interest to society in general. The importance of contiguity, coordination and quantity discounts for making accurate estimates of replacement cost and timing of such pipes was explored in this paper. As the impacts of such discounts on the unit cost of replacement are interconnected and difficult to consider in isolation, 16 unit cost estimates were made for an example network containing $159 \mathrm{~km}$ of cast iron pipe. Overall, such considerations resulted in a $33 \%$ decrease in the unit cost of pipe replacement in the case study and a drop of $23 \%$ in the number of intervention sites with a corresponding increase in the average length of intervention site from $123.7 \mathrm{~m}$ to $162.7 \mathrm{~m}$.

This is a strong indication that in order to make accurate replacement cost and timing estimates of problematic pipes, discounts due to contiguity, coordination and quantity should be calculated and included for all relevant intervention types. This will allow infrastructure managers to take full advantage of economies of scale and renew aging infrastructure at lower costs and potentially at an accelerated time schedule. Of course, the actual magnitude of discounts will vary between utilities and thus accurate parameter estimates are required at the utility level.

\section{REFERENCES}

Carey, B. D. \& Lueke, J. S. 2013. Optimized holistic municipal right-of-way capital improvement planning. Canadian Journal of Civil Engineering, 40, 1244-1251.

Core Team, R. 2013. R: A language and environment for statistical computing. $R$ Foundation for statistical computing, Vienna.

Csardi, G. 2015. igraph $R$ documentation [Online]. CRAN, R package documenation repository. Available: http://igraph.org/r/doc/distances.html [Accessed 28.02.2018].

Infraguide 2003. Selection of Technologies for the Rehabilitation or Replacement of Sections of a Water Distribution System.

Jäggi, A. E. 2018. Swagelining. AQUA \& GAS, 2018.

Kerwin, S. \& Adey, B. T. 2020. Optimal intervention planning. A bottom-up approach to renewing aging water infrastructure. Journal of Water Resources Planning and Management.

Kielhauser, C. \& Adey, B. T. 2018. Determination of intervention programs for multiple municipal infrastructure networks: considering network operator and service costs. Sustainable and Resilient Infrastructure, 1-13.

Kielhauser, C., Adey, B. T. \& Lethanh, N. 2016. Investigation of a static and a dynamic neighbourhood methodology to develop work programs for multiple close municipal infrastructure networks. Structure and Infrastructure Engineering, 1--29.

Kleiner, Y., Nafi, A. \& Rajani, B. 2010. Planning renewal of water mains while considering deterioration, economies of scale and adjacent infrastructure. Water Science and Technology: Water Supply, 10, 897-906.
Kleiner, Y. \& Rajani, B. 2004. Quantifying effectiveness of cathodic protection in water mains: theory. Journal of infrastructure systems, 10, 43-51.

Makar, J., Desnoyers, R. \& McDonald, S. 2001. Failure modes and mechanisms in gray cast iron pipe. Underground Infrastructure Research, 1-10.

Nafi, A. \& Kleiner, Y. Considering economies of scale and adjacent infrastructure works in water main renewal planning. CCWI2009 Conference, 2009a.

Nafi, A. \& Kleiner, Y. 2009b. Scheduling renewal of water pipes while considering adjacency of infrastructure works and economies of scale. Journal of water resources planning and management, 136, 519-530.

Rajani, B. \& Kleiner, Y. 2007. Quantifying effectiveness of cathodic protection in water mains: Case studies. Journal of infrastructure systems, 13, 1-11.

Rajani, B. \& Makar, J. 2000. A methodology to estimate remaining service life of grey cast iron water mains. Canadian Journal of Civil Engineering, 27, 1259-1272.

Tscheikner-Gratl, F., Sitzenfrei, R., Rauch, W. \& Kleidorfer, M. 2016. Integrated rehabilitation planning of urban infrastructure systems using a street section priority model. Urban Water Journal, 13, 28--40.

van Riel, W., Post, J., Langeveld, J., Herder, P. \& Clemens, F. 2017. A gaming approach to networked infrastructure management. Structure and infrastructure Engineering, 13, 855-868.

Zhao, J. Q. \& Rajani, B. 2002. Construction and rehabilitation costs for buried pipe with a focus on trenchless technologies, $\mathrm{NRC}$, Institute for Research in Construction Ottawa, ON. 